\title{
Stochastic risk assessment of urban soils contaminated by heavy metals in Kazakhstan
}

\author{
ELMIRA RAMAZANOVA ${ }^{1}$, WOOJIN LEE ${ }^{2}$ \\ ${ }^{1}$ School of Engineering and Digital Sciences, National \\ Laboratory Astana, Nazarbayev University, Nur-Sultan, \\ Kazakhstan, elmira.ramazanova@nu.edu.kz \\ ${ }^{2}$ School of Engineering and Digital Sciences, National \\ Laboratory Astana, Nazarbayev University, Nur-Sultan, \\ Kazakhstan,woojin.lee@nu.edu.kz
}

Soil contamination with toxic and carcinogenic heavy metals from smelting and mining industries has been a serious environmental problem in Kazakhstan. It might not be easily solved in near future because (1) the impact of soil contamination with heavy metals on Kazakstanese has never been evaluated and (2) soil quality guidelines of Kazakhstan fail to address human health and remediation objectives. We have conducted a stochastic risk assessment for 5 heavy metals $(\mathrm{Pb}, \mathrm{Cd}, \mathrm{Cu}, \mathrm{Zn}, \mathrm{Cr})$ to assess the extent of damage of soil contamination on the people and to check if the soil remediation is needed. Based on the preliminary statistical analysis of 2 cities, the top 4 cities contaminated with heavy metals (Balkhash, Ust-Kamenogorsk, Ridder, and Shymkent) were selected for the risk assessment. Carcinogenic risks higher than the threshold $\left(1 \times 10^{-6}\right)$ were observed in all 4 cities in both adults and children. The probability of the value exceeding the threshold cancer risk varied from 50 (adults) to 93\% (children). The highest cancer risk was observed in Shymkent and Ridder cities. Hazard index (HI) of children were higher than those of adults, reaching values between 1.2 and 3.4 (treshold $=1$ ). The most critical scenario was the oral ingestion of $\mathrm{Pb}$. It contributes to $40 \% \sim 90 \%$ of total $\mathrm{HI}$, while all cases were critical for cancer risk values. The risk assessment has been estimated using the Matlab R2018b (10,000 runs) with country-specific exposure parameters based on the data provided by the government. The results suggest that many people could suffer from relevant diseases including cancer and soil remediation actions are essentially needed in the country. The study was supported by the Research Grant of Nazarbayev University (NLA Contract No. 284-2019//0122019 and 091019CRP2106 ). 